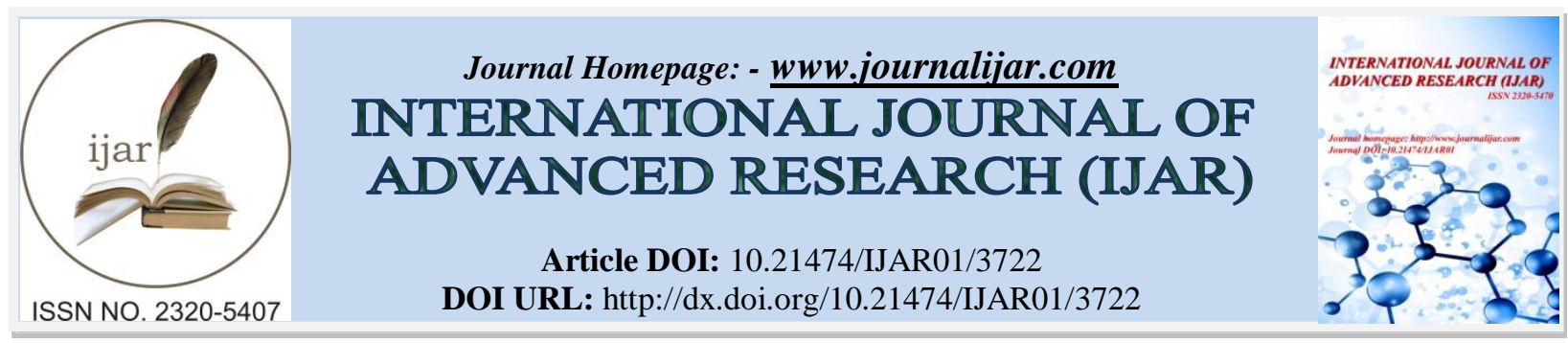

RESEARCH ARTICLE

\title{
SCORPION HEMOCYTE- GRANULOCYTE.
}

\begin{abstract}
U. H. Shah.
Head and Associate Professor, Department of Zoology, Balwant College, Vita- 415311 (Sangli), Maharashtra India.
\end{abstract}

\section{Manuscript Info}

Manuscript History

Received: 15 January 2017

Final Accepted: 08 February 2017

Published: March 2017

Key words:-

Scorpions, Hemocytes, Granulocyte

\section{Abstract}

The study of hemocytes in arthropoda is the most fascinating area of research. The hemocytes are having similarity with that of blood cells in vertebrates. The study of hemocytes is mostly concentrated around insects and the scorpion hemocytes are having limited attention by scientists. In the present investigation granulocytes (GRs) of five different scorpions- Mesobuthus tamulus tamulus, Mesobuthus tamulus concanesis, Orthochirus bicolor, Heterometrus xanthopus and Heterometrus phipsoni, were studied qualitatively as well as quantitatively.

Copy Right, IJAR, 2017,. All rights reserved.

\section{Introduction:-}

The scorpions are the arachnids with open type of circulatory system with hemocoel filled by hemolymph. The hemolymph consists of plasma in which numerous blood cells- hemocytes are suspended and playing vital role in maintains of immunity against various pathogens (Bauchau, 1981). The defense role played by hemocytes is through phagocytosis, encapsulation and by lyses of foreign cells (Soderhall and Cerenius, 1992). The hemocytes are also important for transport of nutrients and harmones at the site of growth and wound healing (Lavine and Strand, 2002). According to Al-Robai et al. (2002), there are three well defined types of hemocytes in arthropodaprohemocyte (PRs), plasmocytes (PLs) and granulocytes (GRs). Some more types of hemocytes are recorded in arthropods are- coagulocytes (COs), spherulocytes (SPs), adipohemocytes (ADs) and oenocytes (OEs). In the present investigation the GRs are studied in scorpions- Mesobuthus tumulus tumulus, Mesobuthus tumulus concanesis, Orthochirous bicolor, Herterometrus xanthopus and Heterometrus phipsoni.

\section{Material And Methods:-}

All five species of scorpions were collected from their natural habitat from different localities of Maharashtra (India). These are placed in perforated jars containing hibiscus leaves, water and cockroaches as their food. The males and females were identified according to sexual dimorphic characters as described by Tikader and Bastawade (1983) and placed in separate jars.

> Collection of hemolymph: The hemolymph was collected from the live animals as explained by Padmanabha (1967). It is collected by aspiration through arthroidal membrane at the third joint of one of the pedipalp. 1 to 3 $\mathrm{ml}$ of hemolymph was collected from single animal.

$>$ Techniques employed to study hemocytes: The hemocytes were studied qualitatively and quantitatively. The methods used to study hemocytes were same that was followed to study vertebrate blood cells. For qualitative study none of the single method was satisfactory, hence combination of different methods were employed. For qualitative study different staining methods used are- Sudan Black B, Giemsa, Janus Green B and Leishman's stain. The hemocytes were observed under light as well phase contrast microscope.The transmission electron 
microscopic (TEM) observation was made for only one sample of $H$. xanthopus. For identifying the granulocytes qualitative methods employed are differential hemocyte count (DHC) and total hemocyte count (THC). For THC Neubauer's hemocytometer was used (Witting, 1966).

\section{Result and Discussion:-}

During the present investigation Jone's classification (Jones, 1962) method was used. According to this method seven types of hemocytes- PRs, PLs, GRs, Ads, OEs and COs are present in the scorpions. These are also reported by Shah and Patil have studied the hemocytes in M. tumulus tumulus (2011) and in O. bicolor (2013).

The GRs are characterized by presence of cytoplasmic granules in it, which are stainable by different stains like Sudan Black B, Giemsa and Leishman's stain. These are generally round to oval in shape. The shapes of the GRs are round in O. bicolor, oval in H. xanthopus, round/ oval in M. tumulus tumulus. The size of GRs is smallest in H. concanesis $(6-12 \mu \mathrm{m})$, while largest in H. phipsoni $(11-15 \mu \mathrm{m})$ in diameter. In M. tumulus tumulus the cell is 9- 15 $\mu \mathrm{m}, 7-14 \mu \mathrm{m}$ in O.bicolor while it is $10-15 \mu \mathrm{m}$ in diameter in H. xanthopus.

The nucleus of all GRs in above five types of scorpions is round in shape. The size of the nucleus is minimum in $M$. concanesis $(3-5 \mu \mathrm{m})$ while largest in $H$. xathopus and $H$. phipsoni $(5-8 \mu \mathrm{m})$ in diameter. The size of the nucleus is 4- $6 \mu \mathrm{m}$ in $M$. tumulus tumulus. The nucleo-ctoplasmic ratio was ranging from 30-70\%. In all the GRs the nucleus was mostly central in position. The cytoplasm and nucleus of all above five GRs are basophilic in nature.

An attempt has been made to study ultra structure of one of the scorpions- H. xanthopus, in which the GRs are with following characteristics-

1. The GRs are almost spherical in shape.

2. The plasma membrane appears smooth.

3. The nucleus is eccentric in position due to presence of granules. The chromatin is scattered with dense clumps. The nucleolus with two zones.

4. The cytoplasmic granules are concentrated near nucleus and measures about $1-3 \mu \mathrm{m}$ in diameter and are of three types- structure less and electron dense, structure less and with small tiny granules, structured granules.

5. The nuclear envelope is perforated by nuclear pores.

According to Gupta (1985) the structured granules by gradual transformed into structure less during maturation and discharged the contents in the hemolymph. In the present investigation during TEM study both types of granules were observed. The microtubules were associated with granules, which were also reported by Akai and Sato (1973) but there are no such structural microtubules are observed. The structured granules become structure less during discharge of its contents in hemolymph as shown in the Plate II. The same findings are reported by Gupta (1985). The chemical nature of the granules was identified by PAS (McManus, 1946) and Sudan Black B (Humason, 1979) methods. These granules are with mucopolysaccharides and lipid in it.

GRs are reported almost in all arthropoda including onychopora (Gupta, 1985a), hence are plesiomorphic hemocytes. Many researchers have reported phagocytic role of GRs (Gupta, 1985a). In the present investigation there were no any pseudopodia like structures are notified. The same findings were reported by Silva et al (2000) in GRs of larva Anastrepha oblique. There is conflicting views about the origin of GRs in arthropoda. Arnold (1974) has suggested that these arise from PRs and PLs. It was also supported by Takada and Kitano (1971). According to Gupta and Sutherland (1966) GRs are capable of giving rise to SPs, Ads and Cos. Arnold (1974) has suggested that "the GRs, might be considered as basic unit from which more precisely structural and functional classes of cells have been developed."

THC was performed in both male and female (Pregnant and non-pregnant) scorpions. The values of THC are lowest in male H. xanthopus (9750 per $\mathrm{mm}^{3}$ ) and highest in H.concanesis $\left(46850\right.$ per $\left.\mathrm{mm}^{3}\right)$. The vales of others are reported in the Table1. The same findings were observed in females. The number of GRS are more in pregnant than non-pregnant females. The $\%$ of GRs was performed by DHC. Higher $\%$ of GRs was reported in M. tamulus concanesis (15\%) while minimum (10\%) in H. xanthopus. The granules of M. tamulus tamulus, M. tamulus concanesis and $O$. bicolor are smaller in size and number of GRs are more while the granules are larger in size in $H$. xanthopus and H.concanesis and number of GRs are less in number. It indicates that there is universe relation between size of granules and number of GRs. 
The hematology of scorpion can be done with ease as large volume of hemolymph can be obtained from single animal. Although Gupta (1986) has pointed out several functional analogies between arthropod immunocytes and vertebrate B- and T- lymphocytes, there is great scope to study it in future. In general the hemocytes of scorpions are similar to those in other arthropods. There are few reports about the study of hemocytes in scorpions. M. tamulus concanesis is one of the most venomous species found in India, whose poison fatal especially in children. Whether this venomous nature is related to high THC or to number of GRs is the matter of further research.

\section{PLATE I}
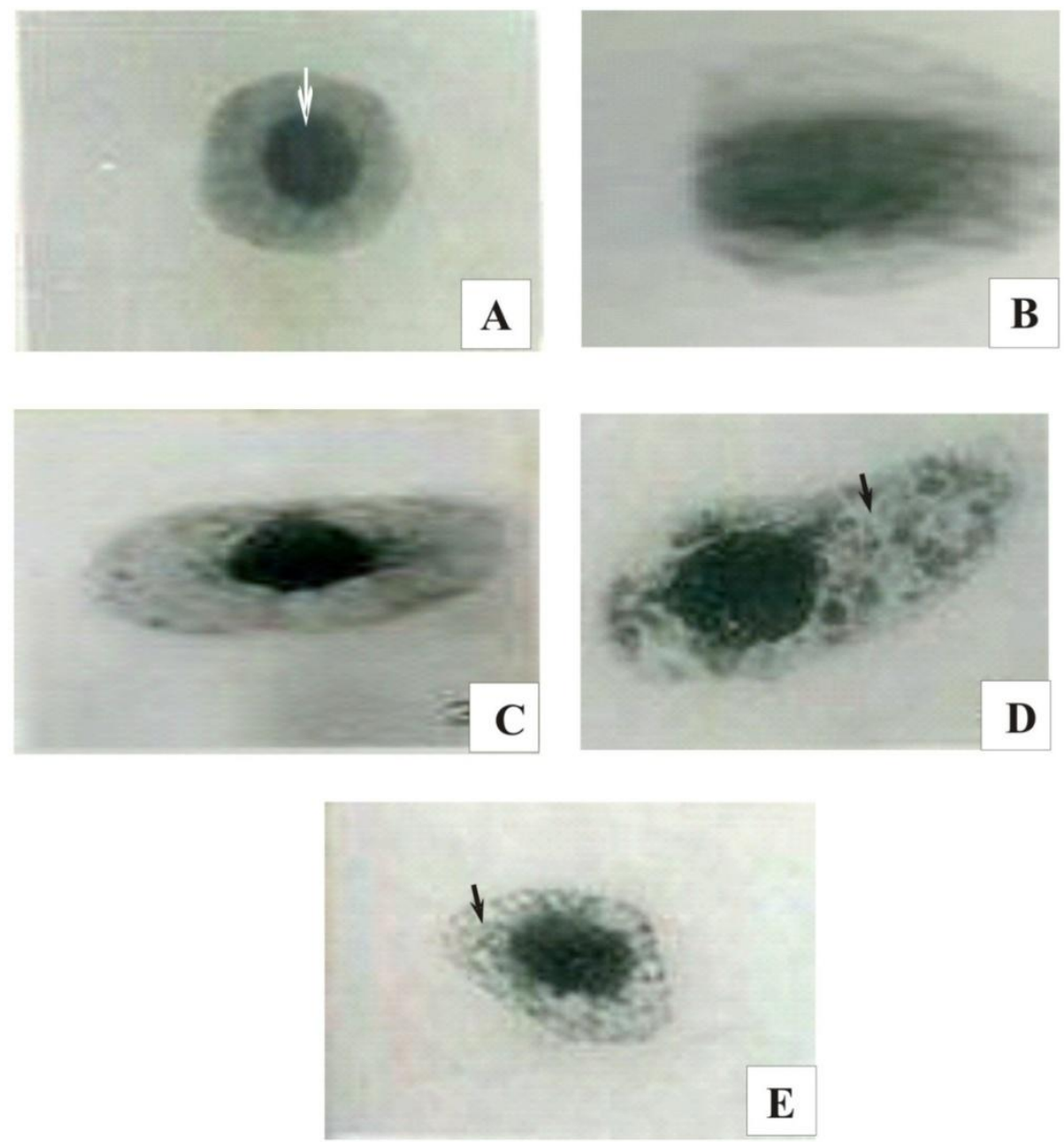

The granulocytes in the scorpions:

A: Mesobuthus tamulus tamulus (X940)

B: Mesobuthus tamulus concanensis (X940)

C: Orthochirus bicolor (X940)

D: Heterometrus xanthopus (X940)

E: Heterometrus phipsoni (X940)

Black arrow- Granules

White arrow- Nucleus 


\section{PLATE II}

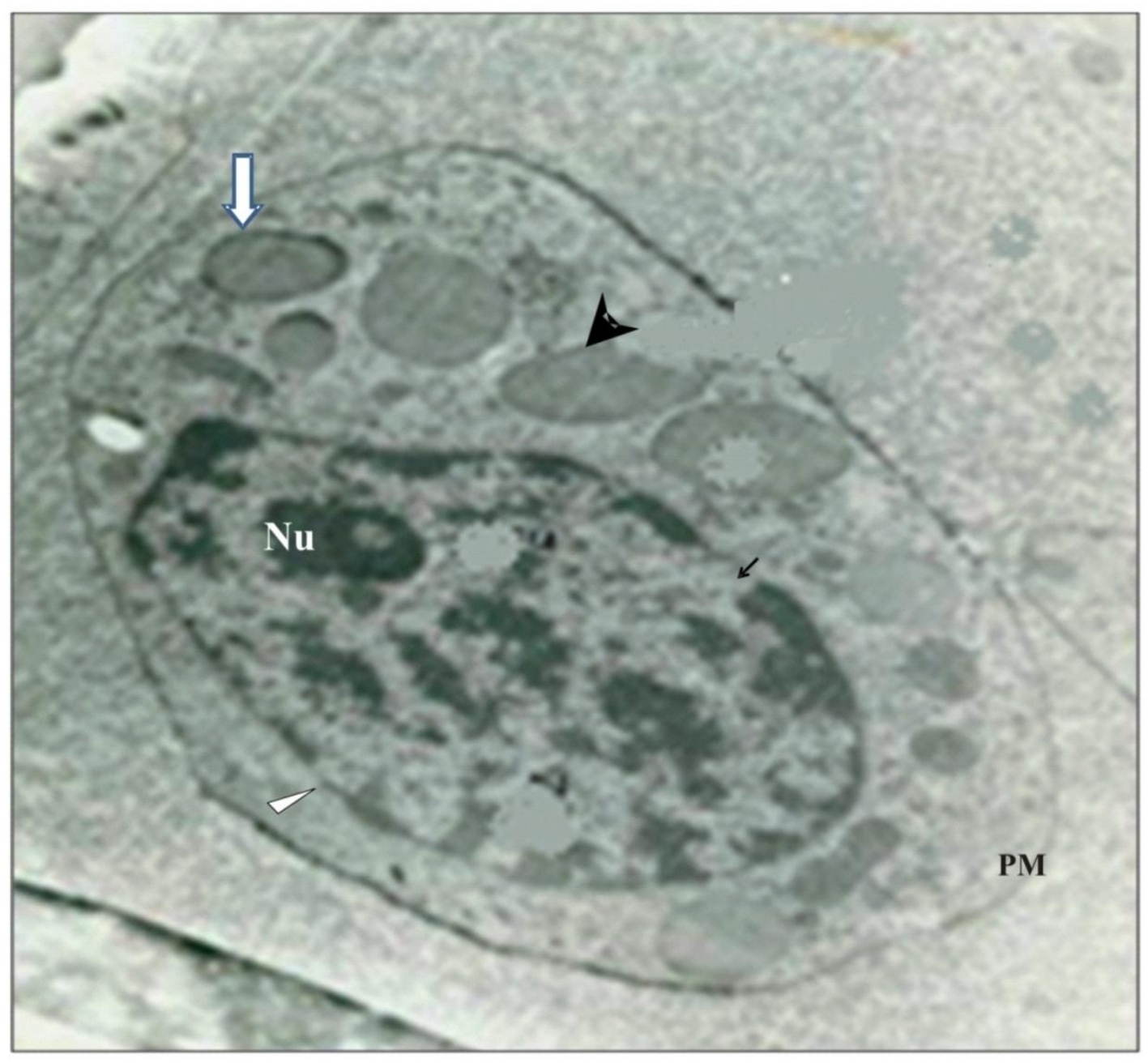

TEM of Granulocyte in Hetrometrus xanthopus (X15000)

Nu: nucleolus $\quad$ PM: Plasma membrane

Black arrow: Nuclear pore

White solid arrow: Membrane bound granules

Black arrow head: Bursting granule

White arrow head: Nucleus 


\section{Referances:-}

1. Akai, H. and Sato, S. (1973). Ultrastructure of the larval Hemocytes of the wild silkworm. Antherea yamamai G. (Lepidoptera: Saturnidae). Jap. J. Appl. Zoo. 22: 225- 233.

2. Arnold, J. W. (1974). The Hemocytes of insects. In: The physiology of insect. (ed.) M. Rockstein, Academic press. 5: 201- 214.

3. Bauchau, A. G. (1981). Crusataceans. In: Ratcliff, N. A., Rowley, A. F. (ed.) Invertebrate blood cells. Vol. II. London Academic Press, 385- 420.

4. Gupta, A. P. (1985). Cellular elements in the hemolymph. In: sinology,Comprehensive insect physiology, biochemistry and pharmacology. (ed.) G. A. KArkut and L. I. Gilbert. Pergamon press. 3: 401- 451.

5. Gupta, A. P. (1985a). Cellular elements in hemolymph. In: A. P. Gupta (ed.) Comprehensive Insect Physiology, Biochemistry and Pharmacology. Pergamon Press. Vol. III. Oxford. Pp. 402- 444.

6. Gupta, A. P. (1986). Arthropod immunocytes: Their identification, structure and functional analogies to those of vertebrate B- and T- lymphocytes. In: Hemocytic and humoral immunity in arthropoda. (ed.) Gupta, A. P., John Wiely ans Sons, New York. Pp. 3- 59.

7. Humasson, G. L. (1970). Animal tissue techniques. (ed.) W. H. Freeman. San Francisco.

8. Lavine, M. D. and Strand, M. R. (2002). Insect Hemocytes and their role in immunity. Insect Biochem. Mol. Biol. 32: 1295- 1309.

9. McManus, J. F. A. (1946). Histochemical demonstration of mucins after periodic acid. Nature. 158: $202-204$.

10. Padmanabha, N. B. (1967). Perfusion fluid for the scorpion, Heterometrus fulvipes. Nature (London. 213: 420).

11. Patil A. E. and Shah, U. H. (2011). Types of Hemocytes in scorpion Mesobuthus tumulus tumulus. The Bioscan. 6: 597- 599.

12. Patil A. E. and Shah, U. H. (2013). The Hemocytes of Orthochirus bicolor. Geobios, 40: $24-29$.

13. Silva, J. E. B., Bolelli, I. C. and Simones, Z. L. P. (2002). Hemocyte types and total and differential counts in unparasitized and parasitized Anastrepha oblique (Dipteria, Tephridiae) larva. Braz. J. Biol. 62 (4a): 689- 699.

14. Soderhall, K. and Cerenis, L. (1992). Crustacean immunity. Annu. Rev. Fish Dist., 2: 3-23.

15. Spicer, S. S., Horn, R. G. and Leppi, T. J. (1967). Histochemistry of connective tissue mucopolysaccharides. In: Int. Acad. Pathol. Monograph. William and Wilkin (ed.) Baltimore. Pp: 251- 303.

16. Takada, M. and Kitano, H. (1971). Studies on larval Hemocytes of Pieris rapae Biosdual, with special reference to hemocyte classification. Phagocytic activity and encapsulation activity (Lep. Pieridae). Kontyo.39: 385 - 394.

17. Tikder, B. K. and Bastawade, D. B. (1983). The fauna of India, scorpion, scorpionoids, arachnida. Vol. III. Director ZSI (ed.), Culcutta. Pp. 9.

18. Witting, G. (1966). Phagocytosis of blood cells in healthy and diseased caterpillars II. A consideration of the method of making hemocyte count. J. Inver. Pathol. 8(4): 461- 477. 